\title{
Non-invasive method to detect high respiratory effort and transpulmonary driving pressures in COVID-19 patients during mechanical ventilation
}

\author{
Lisanne Roesthuis ${ }^{*} \mathbb{0}$, Maarten van den Berg and Hans van der Hoeven
}

\begin{abstract}
Background: High respiratory drive in mechanically ventilated patients with spontaneous breathing effort may cause excessive lung stress and strain and muscle loading. Therefore, it is important to have a reliable estimate of respiratory effort to guarantee lung and diaphragm protective mechanical ventilation. Recently, a novel non-invasive method was found to detect excessive dynamic transpulmonary driving pressure $\left(\Delta P_{L}\right)$ and respiratory muscle pressure $\left(P_{\text {mus }}\right)$ with reasonable accuracy. During the Coronavirus disease 2019 (COVID-19) pandemic, it was impossible to obtain the gold standard for respiratory effort, esophageal manometry, in every patient. Therefore, we investigated whether this novel non-invasive method could also be applied in COVID-19 patients.
\end{abstract}

Methods: $\triangle P_{L}$ and $P_{\text {mus }}$ were derived from esophageal manometry in COVID-19 patients. In addition, $\triangle P_{L}$ and $P_{\text {mus }}$ were computed from the occlusion pressure $\left(\triangle P_{\text {occ }}\right)$ obtained during an expiratory occlusion maneuver. Measured and computed $\Delta P_{\mathrm{L}}$ and $P_{\text {mus }}$ were compared and discriminative performance for excessive $\Delta P_{\mathrm{L}}$ and $P_{\text {mus }}$ was assessed. The relation between occlusion pressure and respiratory effort was also assessed.

Results: Thirteen patients were included. Patients had a low dynamic lung compliance [24 (20-31) $\left.\mathrm{mL} / \mathrm{cmH}_{2} \mathrm{O}\right]$, high $\Delta P_{\mathrm{L}}\left(25 \pm 6 \mathrm{cmH}_{2} \mathrm{O}\right)$ and high $P_{\text {mus }}\left(16 \pm 7 \mathrm{cmH}_{2} \mathrm{O}\right)$. Low agreement was found between measured and computed $\triangle P_{\mathrm{L}}$ and $P_{\text {mus }}$. Excessive $\Delta P_{\mathrm{L}}>20 \mathrm{cmH}_{2} \mathrm{O}$ and $P_{\text {mus }}>15 \mathrm{cmH}_{2} \mathrm{O}$ were accurately detected (area under the receiver operating curve (AUROC) 1.00 [95\% confidence interval (Cl), 1.00-1.00], sensitivity $100 \%(95 \% \mathrm{Cl}, 72-100 \%)$ and specificity $100 \%$ (95\% Cl, 16-100\%) and AUROC 0.98 (95\% Cl, 0.90-1.00), sensitivity 100\% (95\% Cl, 54-100\%) and specificity 86\% (95\% $\mathrm{Cl}, 42-100 \%$ ), respectively). Respiratory effort calculated per minute was highly correlated with $\Delta P_{\text {occ }}$ (for esophageal pressure time product per minute $\left(\mathrm{PTP}_{\mathrm{es} / \mathrm{min}}\right) r^{2}=0.73 ; P=0.0002$ and work of breathing (WOB) $\left.r^{2}=0.85 ; P<0.0001\right)$.

Conclusions: $\Delta P_{\mathrm{L}}$ and $P_{\text {mus }}$ can be computed from an expiratory occlusion maneuver and can predict excessive $\Delta P_{\mathrm{L}}$ and $P_{\text {mus }}$ in patients with COVID-19 with high accuracy.

Keywords: Coronavirus disease 2019, Respiratory monitoring, Occlusion pressure, Dynamic transpulmonary pressure, Respiratory muscle pressure, Respiratory effort

*Correspondence: Lisanne.Roesthuis@Radboudumc.nl

Department of Intensive Care Medicine, Radboud University Medical Center, Geert Grooteplein-Zuid 10,6525 GA Nijmegen, The Netherlands

\section{Background}

Maintaining spontaneous breathing effort in mechanically ventilated patients limits respiratory muscle disuse and atrophy [1-4]. Too high respiratory effort may lead to excessive lung stress and strain causing lung injury on one hand. On the other hand, it may lead to excessive muscle loading causing muscle injury (mainly diaphragm 
injury) leading to muscle dysfunction [5]. High respiratory drive and effort frequently exist in critically ill patients, mainly due to insufficient ventilator assistance and sedation, but evidence also suggests biological predisposition (e.g., pulmonary and systemic inflammation, lung mechanical heterogeneity) plays a role as well. Therefore, it is important to have a reliable estimate of respiratory effort to enable lung and diaphragm protective mechanical ventilation [6-8].

The gold standard to obtain respiratory effort is esophageal manometry. This technique is minimally invasive, requires appropriate equipment and expertise, and can be time consuming. Other monitoring techniques or parameters only reflect respiratory drive $\left(P_{0.1}\right.$ and electrical activity of the diaphragm) or muscle loading (diaphragm ultrasound) and provide only limited information about lung stress and strain (plateau pressure and driving pressure) [7]. Recently, Bertoni et al. [9] demonstrated that dynamic transpulmonary driving pressure $\left(\Delta P_{\mathrm{L}}\right)$ and respiratory muscle pressure $\left(P_{\text {mus }}\right)$ can be estimated from the maximal decline in airway pressure $\left(P_{\mathrm{aw}}\right)$ from positive end-expiratory pressure (PEEP) during an expiratory occlusion maneuver $\left(\Delta P_{\text {oсc }}\right)$. Direct estimates of $\Delta P_{\mathrm{L}}$ and $P_{\text {mus }}$ were unreliable, excessive $\Delta P_{\mathrm{L}}$ and $P_{\text {mus }}$, however, could be predicted with reasonable accuracy.

Coronavirus disease 2019 (COVID-19) is a new type of lung disease [10-12] originating from Wuhan, China, in December 2019. Because of the sheer number of mechanically ventilated patients with severe lung disease, it was impossible to measure esophageal pressure to assess respiratory mechanics in every patient. Therefore, we estimated $\Delta P_{\mathrm{L}}$ and $P_{\text {mus }}$ according to Bertoni et al. [9] in every COVID-19 patient with spontaneous breathing effort as part of standard patient care. If computed $\Delta P_{\mathrm{L}}$ and/or $P_{\text {mus }}$ were excessive (i.e., higher than $P_{\text {mus }}$ 13-15 $\mathrm{cmH}_{2} \mathrm{O}$ and $\left.\Delta P_{\mathrm{L}} 16-17 \mathrm{cmH}_{2} \mathrm{O}\right)$, or if patients received prolonged mechanical ventilation with no progress (i.e., $\geq 14$ days) or if patients remained hypercapnic $\left(\mathrm{PaCO}_{2} \geq 60 \mathrm{mmHg}\right)$, respiratory mechanics was assessed by esophageal manometry for clinical purposes.

The aim of this paper is to describe respiratory mechanics in mechanically ventilated COVID-19 patients with spontaneous breathing effort, to compute $\Delta P_{\mathrm{L}}$ and $P_{\text {mus }}$ from $\Delta P_{\text {occ }}$ and assess the discriminative performance for excessive $\Delta P_{\mathrm{L}}$ and $P_{\text {mus }}$, and to assess the relation between $\Delta P_{\text {occ }}$ and respiratory effort.

\section{Methods}

\section{Study population}

Dynamic transpulmonary driving pressure and respiratory muscle pressure were assessed in COVID19 patients admitted to the Intensive Care Unit of the
Radboud University Medical Center according to Bertoni et al. [9] as follows:

(1) computed $\Delta P_{\mathrm{L}}=\left(\right.$ peak $\left.P_{\text {aw }}-\mathrm{PEEP}\right)-2 / 3 \times \Delta P_{\text {occ }}$.

(2) computed $P_{\text {mus }}=-3 / 4 \times \Delta P_{\text {occ }}$

If patients had high respiratory effort and/or high dynamic transpulmonary driving pressure (i.e., computed $P_{\text {mus }} 13-15 \mathrm{cmH}_{2} \mathrm{O}$ and $\Delta P_{\mathrm{L}} 16-17 \mathrm{cmH}_{2} \mathrm{O}$ or higher), prolonged mechanical ventilation without clinical progress (i.e., $\geq 14$ days) or remained hypercapnic $\left(\mathrm{PaCO}_{2} \geq 60 \mathrm{mmHg}\right)$, esophageal manometry was obtained as part of our standard clinical protocol. Patients or their legal representatives were informed about the measurements.

\section{Study protocol}

This was an observational study. All patients were ventilated with a Servo-i/u ventilator (Getinge, Sölna, Sweden). Ventilator settings were set by the treating intensivist. Patients received a nasogastric catheter with esophageal balloon [Cooper (Cooper Surgical, Trumbull, USA) or Neurovent (NeuroVent Research Inc, Toronto, Canada)] to obtain esophageal pressure $\left(P_{\text {es }}\right)$. Catheter position was validated using the dynamic occlusion test [13]. A total of 3-4 manual expiratory occlusions (lasting $\sim 1-2 \mathrm{~s}$ ) were performed during a $10-15$ min recording per patient. After the recordings, ventilator settings or sedation strategies were adjusted, if deemed necessary, in accordance with the treating intensivist. Being an observational study, the effect of different ventilator settings or sedatives was not investigated.

\section{Data acquisition}

Ventilator flow and airway pressure $\left(P_{\text {aw }}\right)$ were obtained (sample frequency $100 \mathrm{~Hz}$ ) by connecting a RS-232 cable via the serial port of the Servo-i/u to a dedicated measurement set-up using Servotracker software (Servotracker release 4.2, Getinge, Sölna, Sweden). The esophageal balloon (i.e., $P_{\text {es }}$ ) and a T-piece connected to the expiration port of Servo-i/u (i.e., $P_{\mathrm{aw}}$ ) were coupled to pressure transducers and acquired (sample frequency $100 \mathrm{~Hz}$ ) using a dedicated measurement set-up (Biopac MP160, BIOPAC Inc., USA). Signals were synchronized offline based on $P_{\text {aw }}$ tracings that were acquired using both software programs. Brief manual expiratory occlusions (lasting $\sim 1-2 \mathrm{~s}$ ) were performed to enable offline synchronization. Data were processed and analyzed offline using Matlab R2018a (Mathworks, Natick, MA, USA). 


\section{Signal analysis}

The occlusion pressure $\left(\Delta P_{\text {occ }}\right)$ was defined as the maximal deflection in $P_{\text {aw }}$ from positive end-expiratory pressure (PEEP) during an expiratory occlusion maneuver (Fig. 1). The decrease in $P_{\text {es }}$ during the first $100 \mathrm{~ms}$ of this maneuver was computed as $P_{0.1}$. Transpulmonary pressure $\left(P_{\mathrm{L}}\right)$ was determined by subtracting $P_{\mathrm{es}}$ from $P_{\text {aw }}$. Dynamic transpulmonary driving pressure $\left(\Delta P_{\mathrm{L}}\right)$ was computed from onset to peak during inspiration. Dynamic lung compliance $\left(C_{\mathrm{dyn}}\right)$ was calculated as tidal volume divided by the increase in $P_{\mathrm{L}}$ between points of zero flow. Chest wall elastance $\left(E_{\mathrm{cw}}\right)$ was estimated based on predicted vital capacity $[9,14]$, from this chest wall elastic recoil pressure $\left(P_{\mathrm{cw}}\right)$ was computed as the product of tidal volume and $E_{\mathrm{cw}}$. The pressure generated by the respiratory muscles $\left(P_{\text {mus }}\right)$ was calculated as $P_{\mathrm{cw}}$ minus $P_{\mathrm{es}}$. The integral of the product of $P_{\text {mus }}$ and tidal volume represents work of breathing (WOB), calculated per liter and per minute. The integral of $P_{\text {mus }}$ over time is defined as esophageal pressure-time product $\left(\mathrm{PTP}_{\mathrm{es}}\right)$, calculated per breath and per minute [14, 15].

Data obtained during expiratory occlusion maneuvers were averaged. Data were analyzed on a breath-by-breath basis and averaged over at least a 4-min period free of artifacts or esophageal contractions. Only recordings where $\Delta P_{\text {es }} / \Delta P_{\text {occ }}$ was between 0.8 and 1.2 were included in the analysis.

\section{Statistical analysis}

Normality was tested and data are presented accordingly as mean \pm standard deviation (SD) or as median [interquartile range (IQR)]. Measured and computed $\Delta P_{\mathrm{L}}$ and $P_{\text {mus }}$ were compared using Bland-Altman analysis. Receiver operating characteristic curve analysis was performed and sensitivity and specificity were computed to assess the accuracy of computed $\Delta P_{\mathrm{L}}$ and $P_{\text {mus }}$ to detect excessive $\Delta P_{\mathrm{L}}>20 \mathrm{cmH}_{2} \mathrm{O}$ and $P_{\text {mus }}>10$ and $>15 \mathrm{cmH}_{2} \mathrm{O}$. Linear regression analysis was performed to assess the relationship between $\Delta P_{\text {occ }}$ and respiratory effort. For all tests a two-tailed $P<0.05$ was considered statistically significant. Statistical analyses were performed with Prism 5 (Graphad software, San Diego, USA).

\section{Results}

\section{Patient characteristics}

Esophageal manometry was obtained in 15 COVID19 patients between April and July 2020. Two patients were excluded from analysis due to incorrect $\Delta P_{\mathrm{es}} / \Delta P_{\mathrm{occ}}$. Patient characteristics at time of measurement are shown in Table 1. In general, patients were $61 \pm 9$ years old, had high $\mathrm{PaCO}_{2}(63 \pm 17 \mathrm{mmHg})$ and received prolonged mechanical ventilation ( $41 \pm 32$ days). Respiratory failure was the main problem.

Respiratory parameters are shown in Table 2. Only in patient 7 it was not possible to analyze a 4-min period due to continuous esophageal contractions. Patients had

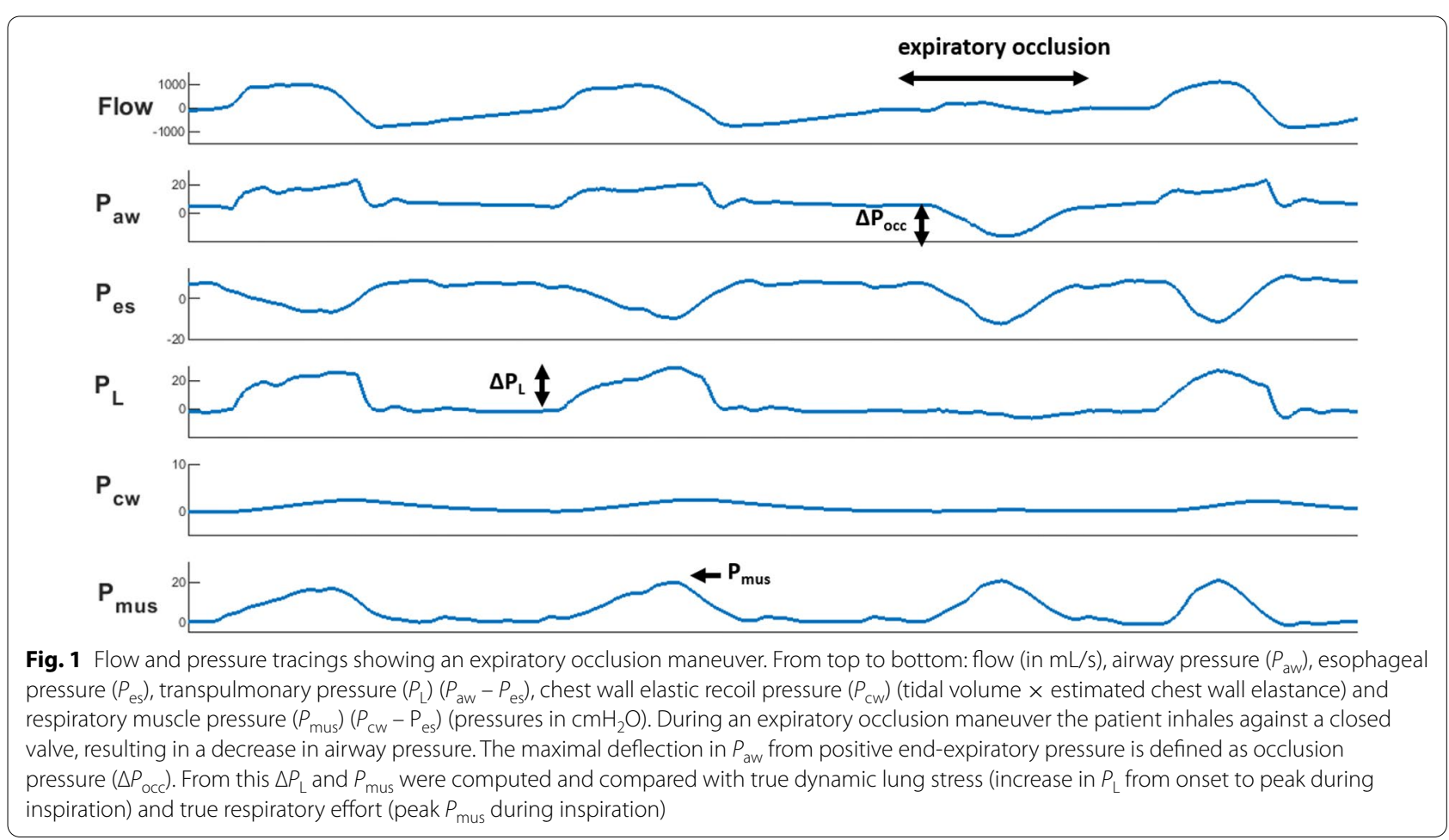


Table 1 Patient characteristics

\begin{tabular}{|c|c|c|c|c|c|c|c|c|c|}
\hline Subject & Age & Gender & Main medical history & Position & $\mathrm{PaO}_{2} / \mathrm{FiO}_{2}$ ratio & $\mathrm{pH}$ & $\begin{array}{l}\mathrm{PaCO}_{2} \\
(\mathrm{mmHg})\end{array}$ & RASS & $\begin{array}{l}\text { Days of MV } \\
\text { on study day }\end{array}$ \\
\hline 1 & 62 & M & - & $P$ & 175 & 7.26 & 74 & -5 & 17 \\
\hline 2 & 71 & M & Asthma, ABPA & S & 216 & 7.43 & 59 & -4 & 4 \\
\hline 3 & 69 & M & $2 \times \mathrm{PCl}$ & S & 116 & 7.25 & 94 & -4 & 22 \\
\hline 4 & 73 & M & COPD Gold II & S & 262 & 7.22 & 64 & -3 & 38 \\
\hline 5 & 51 & M & Waldeström disease & S & 156 & 7.36 & 57 & -4 & 14 \\
\hline 6 & 49 & M & - & $P$ & 78 & 7.42 & 47 & -5 & 6 \\
\hline 7 & 66 & M & OSAS, asthma & S & 182 & 7.47 & 40 & +1 & 42 \\
\hline 8 & 63 & M & Hypertension, obesity & S & 118 & 7.31 & 97 & -4 & 46 \\
\hline 9 & 53 & M & Hodgkin & $P$ & 168 & 7.42 & 47 & -4 & 21 \\
\hline 10 & 47 & $\mathrm{~F}$ & Hypertension & S & 336 & 7.42 & 47 & 0 & 66 \\
\hline 11 & 62 & M & - & $s-L$ & 251 & 7.41 & 63 & 0 & 80 \\
\hline 12 & 69 & M & CABG & S & 155 & 7.38 & 74 & 0 & 109 \\
\hline 13 & 63 & M & OSAS, hypertension & S & 148 & 7.33 & 62 & -1 & 74 \\
\hline
\end{tabular}

$A B P A$ allergic bronchopulmonary aspergillosis, $A K I$ acute kidney injury, $C A B G$ coronary artery bypass grafting, COPD chronic obstructive pulmonary disease, OSAS obstructive sleep apnea syndrome, $\mathrm{FiO}_{2}$ fraction of inspired oxygen, $\mathrm{MV}$ mechanical ventilation, $\mathrm{P}$ prone, $\mathrm{PaCO} \mathrm{C}_{2}$ partial pressure of carbon dioxide in arterial blood, $\mathrm{PaO}_{2}$ partial pressure of oxygen in arterial blood, $P C l$ percutaneous coronary intervention, $S$ supine, $s$ - $L$ semi-lateral due to decubitus

a low $C_{\text {dyn }}\left[24(20-31) \mathrm{mL} / \mathrm{cmH}_{2} \mathrm{O}\right]$, high $\Delta P_{\mathrm{L}}(25 \pm 6$ $\left.\mathrm{cmH}_{2} \mathrm{O}\right)$ and high $P_{\text {mus }}\left(16 \pm 7 \mathrm{cmH}_{2} \mathrm{O}\right)$.

\section{Computed $\Delta P_{\mathrm{L}}$ and $P_{\text {mus }}$}

Bland-Altman analysis showed low bias, but wide limits of agreement between measured and computed $\Delta P_{\mathrm{L}}$ [- 1.1 $\pm 5.9 \mathrm{cmH}_{2} \mathrm{O}$ (bias $\pm 95 \%$ limits of agreement)] (Fig. 2a). Bias between measured and computed $P_{\text {mus }}$ was higher and limits of agreement were equally wide $\left(2.3 \pm 6.0 \mathrm{cmH}_{2} \mathrm{O}\right)$ (Fig. 2b). This means there is poor agreement between measured and computed $\Delta P_{\mathrm{L}}$ and $P_{\text {mus }}$

Receiver operating characteristic curve analysis was performed to assess the discriminative performance to predict excessive dynamic lung stress and respiratory effort (Fig. 3; Table 3). Excessive $\Delta P_{\mathrm{L}}>20 \mathrm{cmH}_{2} \mathrm{O}$ was accurately predicted by computed $\Delta P_{\mathrm{L}}>19 \mathrm{cmH}_{2} \mathrm{O}$ [with area under the receiver operating curve (AUROC) 1.00 (95\% confidence interval (CI), 1.00-1.00), sensitivity $100 \%(95 \%$ CI, $72-100 \%)$ and specificity $100 \%(95 \%$ CI, 16-100\%)]. Discriminative performance for $P_{\text {mus }}>10$ $\mathrm{cmH}_{2} \mathrm{O}$ was only moderate, but was acceptable for $P_{\text {mus }}>15 \mathrm{cmH}_{2} \mathrm{O}$ with computed $P_{\text {mus }}>13 \mathrm{cmH}_{2} \mathrm{O}$ [with AUROC 0.98 (95\% CI, 0.90-1.00), sensitivity 100\% (95\% CI, $54-100 \%$ ) and specificity $86 \%$ (95\% CI, 42-100\%)] (Fig. 3).

\section{$\Delta P_{\text {occ }}$ and respiratory effort}

$\Delta P_{\text {occ }}$ was correlated with respiratory effort (Fig. 4). Only moderate correlations were found between $\Delta P_{\text {occ }}$ and PTP es breath $\left(r^{2}=0.51 ; P=0.0060\right)$ and WOB (calculated per liter) $\left(r^{2}=0.68 ; P=0.0005\right)$. Respiratory effort calculated per minute showed much better correlations with $\Delta P_{\text {occ }}$ (for $\mathrm{PTP}_{\mathrm{es} / \mathrm{min}} r^{2}=0.73 ; P=0.0002$ and WOB $\left.r^{2}=0.85 ; P<0.0001\right)$.

\section{Discussion}

We demonstrate that the mechanically ventilated COVID-19 patients with spontaneous breathing effort included in this study received prolonged mechanical ventilation, had a low dynamic lung compliance, high dynamic transpulmonary driving pressures and high respiratory effort. Dynamic transpulmonary driving pressure and respiratory muscle pressure were estimated from the maximal decline in airway pressure from PEEP during an expiratory occlusion maneuver. Computed $\Delta P_{\mathrm{L}}$ and $P_{\text {mus }}$ are unreliable for direct estimates of $\Delta P_{\mathrm{L}}$ and $P_{\text {mus }}$ derived from esophageal manometry, as analysis showed poor agreement between computed and measured values. However, they can predict excessive $\Delta P_{\mathrm{L}}$ $\left(>20 \mathrm{cmH}_{2} \mathrm{O}\right)$ and $P_{\text {mus }}\left(>15 \mathrm{cmH}_{2} \mathrm{O}\right)$ with high sensitivity and specificity. The occlusion pressure is highly correlated with respiratory effort per minute.

\section{Dynamic lung stress and respiratory effort}

Maintaining spontaneous breathing effort during mechanical ventilation has become increasingly important in recent years, due to accumulating evidence for over-assistance myotrauma not only during controlled mechanical ventilation, but also during high levels of pressure support ventilation [1-5]. Too high respiratory effort, however, can also cause lung and/or diaphragm injury. This might not be that obvious when relying only on plateau and driving pressures on the ventilator 


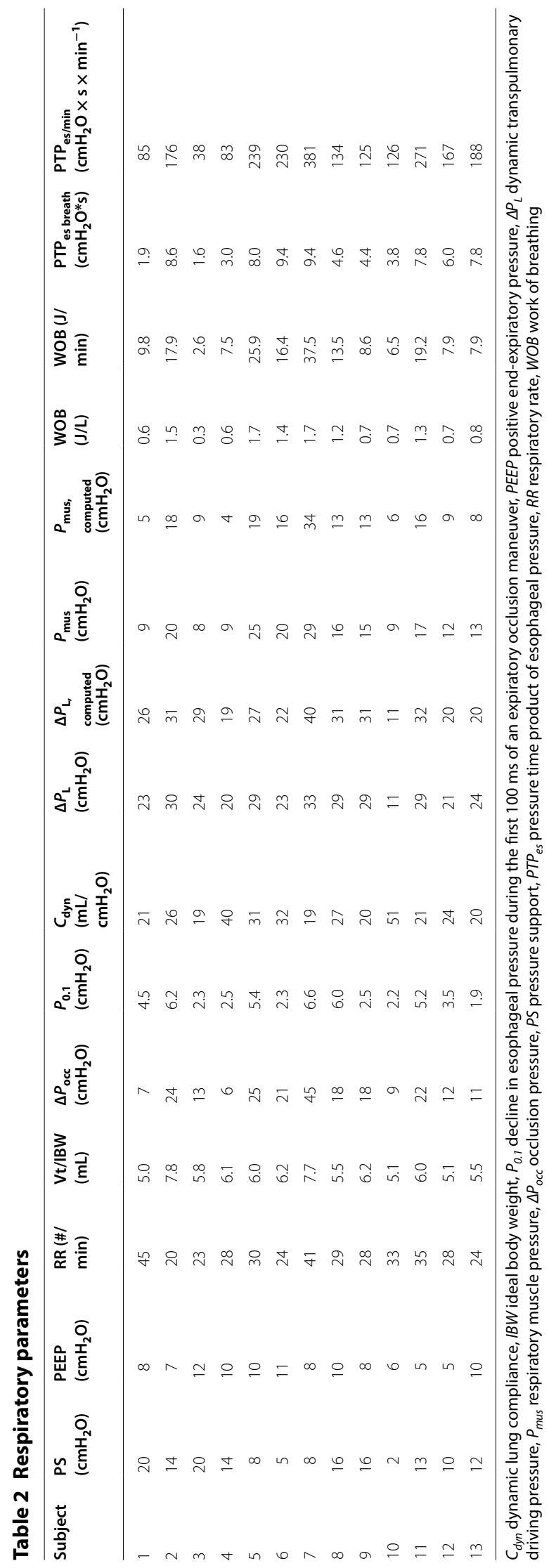



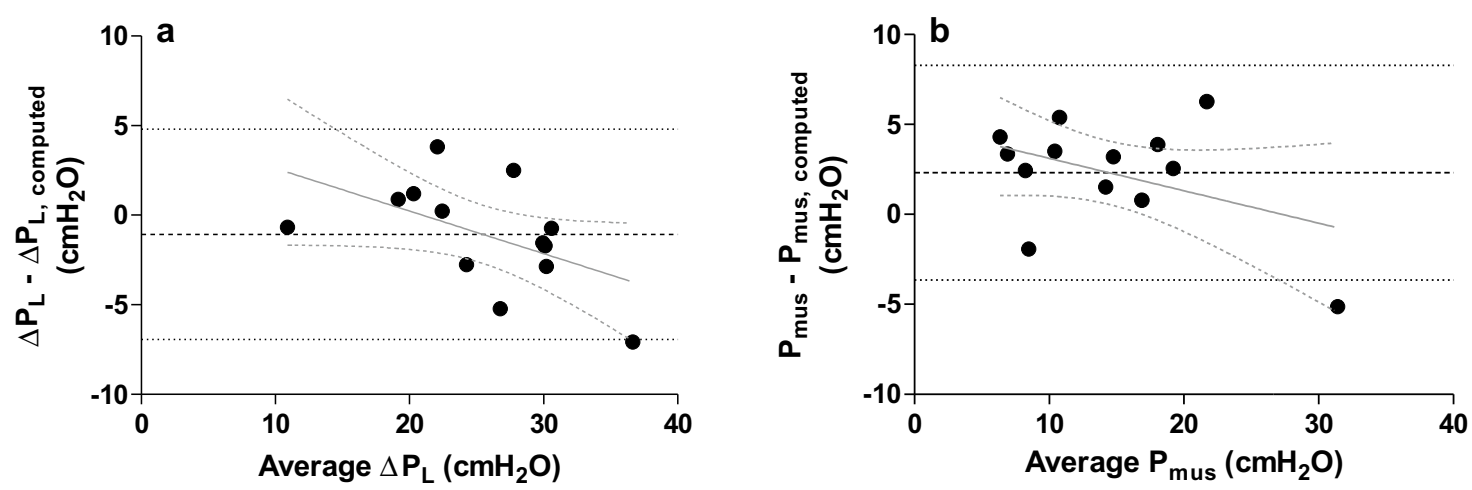

Fig. 2 Bland-Altman plots with regression lines in which measured and computed dynamic transpulmonary driving pressure $\left(\Delta P_{\mathrm{L}}\right)(\mathbf{a})$ and respiratory muscle pressure $\left(P_{\text {mus }}\right)(\mathbf{b})$ are compared. Computed $\Delta \mathrm{P}_{\mathrm{L}}$ overestimates measured $\Delta P_{\mathrm{L}}(\mathbf{a})\left(-1.1 \pm 5.9 \mathrm{cmH}_{2} \mathrm{O}\right.$ (bias $\pm 95 \%$ limits of agreement), while computed $P_{\text {mus }}$ underestimates measured $P_{\text {mus }}(\mathbf{b})\left(2.3 \pm 6.0 \mathrm{cmH}_{2} \mathrm{O}\right)$. Limits of agreement are large for both parameters. There was no significant trend in differences (for $\Delta P_{L} r^{2}=0.27 ; P=0.06$ and for $P_{\text {mus }} r^{2}=0.18 ; P=0.15$ )
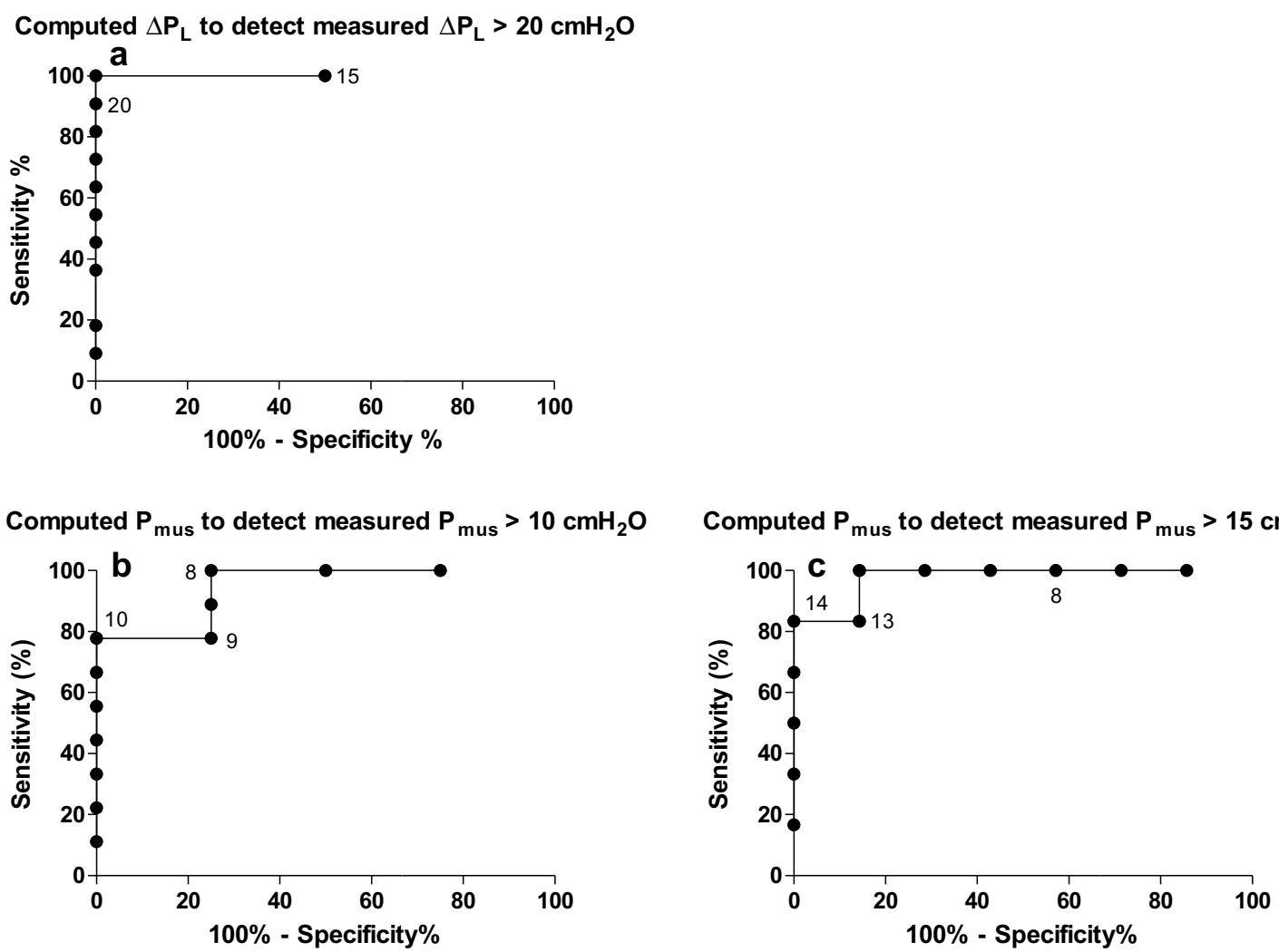

Fig. 3 Receiver operating characteristic curves (ROC) showing the discriminative performance of computed transpulmonary driving pressure $\left(\triangle P_{L}\right)$ to detect measured excessive ( $\left.>20 \mathrm{cmH}_{2} \mathrm{O}\right) \triangle P_{\mathrm{L}}$ [area under the ROC (AUROC) 1.00 (95\% confidence interval (Cl), 1.00-1.00)] (a) and computed respiratory muscle pressure $\left(P_{\text {mus }}\right)$ to detect measured $P_{\text {mus }}>10 \mathrm{cmH}_{2} \mathrm{O}$ [AUROC $\left.0.94(95 \% \mathrm{Cl}, 0.81-1.00)\right]$ (b) and $15 \mathrm{cmH}_{2} \mathrm{O}(\mathrm{AUROC} 0.98(95 \% \mathrm{Cl}$, 0.90-1.00)] (c). Threshold values are shown as points on the curves

screen. The pressure generated by the respiratory muscles (i.e., $P_{\text {mus }}$ ) might in fact be quite high and thus the pleural pressure (i.e., $P_{\mathrm{es}}$ ) quite negative, despite high levels of pressure support. Indirect evidence suggests that high $P_{\text {mus }}$ may cause load-induced muscle injury and dysfunction $[5,6]$. Negative pleural pressures in an already injured lung increase transpulmonary pressures and thus lung stress and strain and worsen vascular 
Table 3 Discriminative performance

\begin{tabular}{|c|c|c|c|c|c|}
\hline Parameter & $\begin{array}{l}\text { Threshold measured } \\
\text { value }\end{array}$ & $\begin{array}{l}\text { Threshold computed value } \\
\text { for excessive value }\end{array}$ & $\begin{array}{l}\text { Area under receiver } \\
\text { operating } \\
\text { characteristic curve } \\
(95 \% \mathrm{Cl})\end{array}$ & Sensitivity $(95 \% \mathrm{Cl})$ & Specificity $(95 \% \mathrm{Cl})$ \\
\hline \multirow{3}{*}{$\begin{array}{l}\text { Excessive dynamic } \\
\text { lung stress }\end{array}$} & \multirow{3}{*}{$\Delta P_{\mathrm{L}}>20 \mathrm{cmH}_{2} \mathrm{O}$} & Computed $\Delta P_{\mathrm{L}}>18 \mathrm{cmH}_{2} \mathrm{O}$ & \multirow[t]{3}{*}{$1.00(1.00-1.00)$} & $100 \%(72-100 \%)$ & $50 \%(1-99 \%)$ \\
\hline & & Computed $\Delta P_{\mathrm{L}}>19 \mathrm{cmH}_{2} \mathrm{O}$ & & $100 \%(72-100 \%)$ & $100 \%(16-100 \%)$ \\
\hline & & Computed $\Delta P_{\mathrm{L}}>20 \mathrm{cmH}_{2} \mathrm{O}$ & & $91 \%(59-100 \%)$ & $100 \%(16-100 \%)$ \\
\hline \multirow{6}{*}{$\begin{array}{l}\text { Excessive respiratory } \\
\text { effort }\end{array}$} & \multirow[t]{3}{*}{$P_{\text {mus }}>10 \mathrm{cmH}_{2} \mathrm{O}$} & Computed $P_{\text {mus }}>8 \mathrm{cmH}_{2} \mathrm{O}$ & \multirow[t]{3}{*}{$0.94(0.81-1.00)$} & $100 \%(66-100 \%)$ & 75\% (19-99\%) \\
\hline & & Computed $P_{\text {mus }}>9 \mathrm{cmH}_{2} \mathrm{O}$ & & $78 \%(40-100 \%)$ & 75\% (19-99\%) \\
\hline & & Computed $P_{\text {mus }}>10 \mathrm{cmH}_{2} \mathrm{O}$ & & $78 \%(40-97 \%)$ & $100 \%(40-100 \%)$ \\
\hline & \multirow[t]{3}{*}{$P_{\text {mus }}>15 \mathrm{cmH}_{2} \mathrm{O}$} & Computed $P_{\text {mus }}>13 \mathrm{cmH}_{2} \mathrm{O}$ & \multirow[t]{3}{*}{$0.98(0.90-1.00)$} & $100 \%(54-100 \%)$ & $86 \%(42-100 \%)$ \\
\hline & & Computed $P_{\text {mus }}>14 \mathrm{cmH}_{2} \mathrm{O}$ & & $83 \%(36-100 \%)$ & $100 \%(59-100 \%)$ \\
\hline & & Computed $P_{\text {mus }}>15 \mathrm{cmH}_{2} \mathrm{O}$ & & $83 \%(36-100 \%)$ & $100 \%(59-100 \%)$ \\
\hline
\end{tabular}

$\Delta P_{L}$ dynamic transpulmonary driving pressure, $P_{\text {mus }}$ respiratory muscle pressure
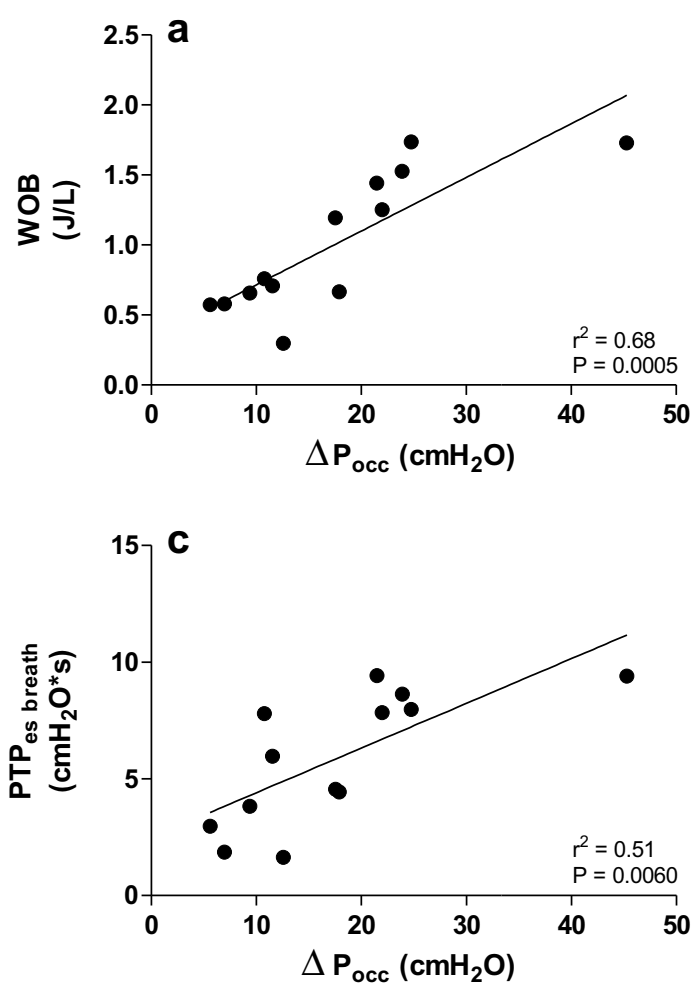
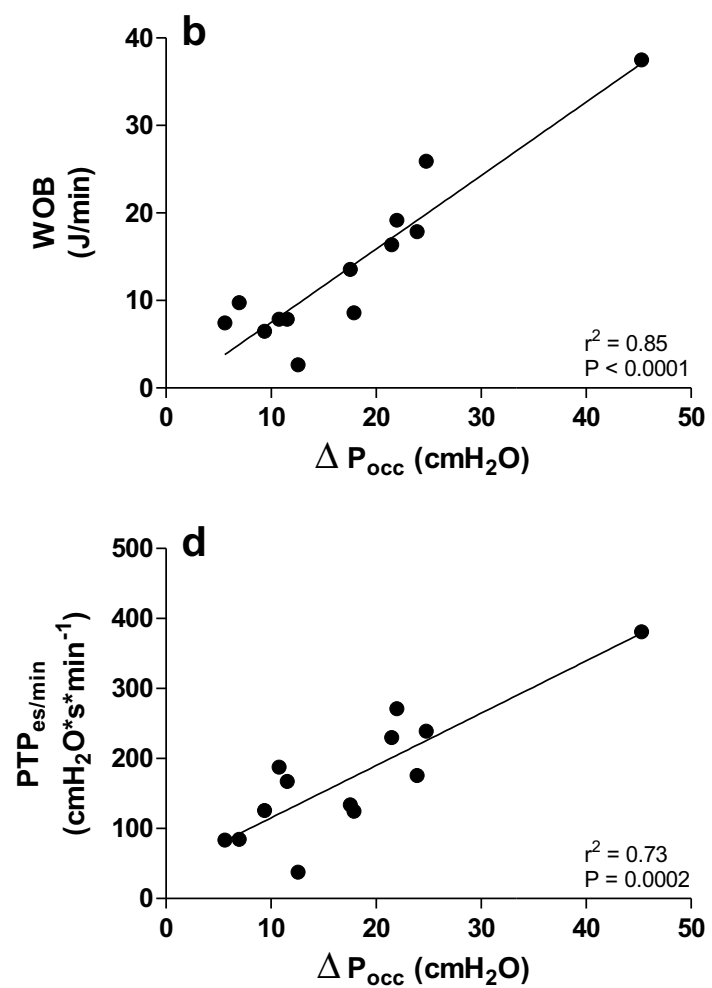

Fig. 4 Relation between occlusion pressure $\left(\triangle P_{\text {occ }}\right)$ and respiratory effort. $\Delta P_{\text {occ }}$ is moderately correlated with work of breathing (WOB) calculated per liter $(\mathbf{a})$ and pressure time product of esophageal pressure per breath $\left(\mathrm{PTP}_{\text {es breath }}\right)(\mathbf{c})$. Higher correlations were found between $\Delta P_{\text {occ }}$ and respiratory effort when respiratory effort was calculated per minute $(\mathbf{b}, \mathbf{d})$

leakage [i.e., patient-self inflicted lung injury (P-SILI)] [16]. In our study, patients had a relatively high $P_{\text {mus }}$ and $\mathrm{PaCO}_{2}$. Apparently, they were not able to increase $P_{\text {mus }}$ to achieve a normal $\mathrm{PaCO}_{2}$. Patients had a high respiratory frequency, but this was insufficient in most patients to meet ventilatory demands as they had high dead space ventilation reflecting severe gas exchange disorders (Additional file 1: Table S1) [17]. $\Delta P_{\text {occ }}$ was only moderately correlated with $\mathrm{PTP}_{\text {es breath }}$ and WOB $(\mathrm{J} / \mathrm{L})$, but highly correlated when respiratory effort was multiplied 
with respiratory frequency [i.e., $\mathrm{PTP}_{\mathrm{es} / \mathrm{min}}$ and $\mathrm{WOB}(\mathrm{J} /$ min)]. Telias et al. [18] observed something similar for $P_{0.1}$, which correlated better with respiratory effort per minute as compared to respiratory effort per breath. Together, the data from our study and the study of Telias et al. [18] suggest that in response to high respiratory drive critically ill patients increase respiratory frequency rather than tidal volume, probably due to a combination of respiratory muscle weakness and decreased lung compliance, limiting the ability to increase effort per breath $[7,19,20]$.

\section{Clinical implications}

Bertoni et al. [9] provided a novel non-invasive method to compute $\Delta P_{\mathrm{L}}$ and $P_{\text {mus }}$ from $\Delta P_{\text {occ }}$ in mechanically ventilated patients with spontaneous breathing effort. We demonstrated that this novel method can also be applied in COVID-19 patients. In accordance with Bertoni et al. [9], computed $\Delta P_{\mathrm{L}}$ and $P_{\text {mus }}$ cannot directly replace $\Delta P_{\mathrm{L}}$ and $P_{\text {mus }}$ derived from esophageal manometry. In the external validation cohort they found reasonable discriminative performance for $\Delta P_{\mathrm{L}}>15 \mathrm{cmH}_{2} \mathrm{O}$ and $P_{\text {mus }}>10 \mathrm{cmH}_{2} \mathrm{O}$. In this study, we were able to show that computed values can also be used to predict excessive $\Delta P_{\mathrm{L}}\left(>20 \mathrm{cmH}_{2} \mathrm{O}\right)$ and $P_{\text {mus }}\left(>15 \mathrm{cmH}_{2} \mathrm{O}\right)$. This is very useful when it is not feasible to perform esophageal manometry for various reasons.

COVID-19 patients have severely injured lungs and are prone to high respiratory effort, necessitating close monitoring to enable lung and diaphragm protective ventilation [6, 8]. If computed $\Delta P_{\mathrm{L}}$ and/or $P_{\text {mus }}$ are/is excessively high, one can decide to measure esophageal pressures. If that is not feasible, ventilator settings should be changed followed by appropriate sedation to keep computed $\Delta P_{\mathrm{L}}$ and $P_{\text {mus }}$ within the clinically acceptable range based on most recent studies and reviews [6, 8, 9]. Excessive sedation, however, can lead to insufficient respiratory effort (i.e., diminished $\Delta P_{\text {occ }}$ ) and increased patient ventilator asynchronies [8].

\section{Limitations}

This study has some limitations. First, the relatively small sample size. However, many physiological studies with critically ill patients are limited in sample size. For example, the external validation cohort in the study by Bertoni et al. [9] only included 12 patients. Second, there is a selection bias. Only patients with computed high respiratory effort and/or high dynamic transpulmonary driving pressure, prolonged mechanical ventilation and/or who were hypercapnic, were included in the study. Therefore, we found relatively high measured $\Delta P_{\mathrm{L}}$ and $P_{\text {mus }}$. Third, limitations in measured $\Delta P_{\mathrm{L}}$ and $P_{\text {mus }}$. $\Delta P_{\mathrm{L}}$ is the dynamic transpulmonary driving pressure, therefore it may overestimate lung stress due to the resistance component. Some studies suggest to perform an end-inspiratory occlusion maneuver in the presence of spontaneous breathing activity to obtain semi-static pressure measurements [21, 22]. For $P_{\text {mus }}$ calculations the chest wall elastance was estimated based on predicted vital capacity. Bertoni et al. [9] demonstrated that predicted values approximated measured values of chest wall elastance.

\section{Conclusions}

In mechanically ventilated COVID-19 patients with spontaneous breathing effort $\Delta P_{\mathrm{L}}$ and $P_{\text {mus }}$ can be computed from an expiratory occlusion maneuver. Computed $\Delta P_{\mathrm{L}}$ and $P_{\text {mus }}$ cannot replace $\Delta P_{\mathrm{L}}$ and $P_{\text {mus }}$ derived from esophageal manometry, but they can predict excessive $\Delta P_{\mathrm{L}}$ and $P_{\text {mus }}$ with high accuracy. The occlusion pressure is highly correlated with respiratory effort per minute.

\section{Supplementary Information}

The online version contains supplementary material available at https://doi. org/10.1186/s13613-021-00821-9.

Additional file 1: Table S1 Dead space ventilation.

\section{Abbreviations}

ABPA: Allergic bronchopulmonary aspergillosis; AUROC: Area under the receiver operating characteristic curve; $\mathrm{CABG}$ : Coronary artery bypass grafting; $C_{\text {dyn }}$ : Dynamic lung compliance; $C l$ : Confidence interval; COPD: Chronic obstructive pulmonary disease; COVID-19: Coronavirus disease 2019; $E_{\mathrm{cW}}$ Chest wall elastance; $\mathrm{FiO}_{2}$ : Fraction of inspired oxygen; IQR: Interquartile range; OSAS: Obstructive sleep apnea syndrome; MV: Mechanical ventilation; $P_{0.1}$ : Decline in esophageal pressure during the first $100 \mathrm{~ms}$ of an expiratory occlusion maneuver; $\mathrm{PaCO}_{2}$ : Partial pressure of carbon dioxide in arterial blood; $\mathrm{PaO}_{2}$ : Partial pressure of oxygen in arterial blood; $P_{\text {aw }}$ : Airway pressure; $\mathrm{PCl}$ : Percutaneous coronary intervention; $P_{c W}$ : Chest wall elastic recoil pressure; PEEP: Positive end-expiratory pressure; $P_{\text {es }}$ : Esophageal pressure; $(\triangle) P_{L}$ : (Dynamic) transpulmonary driving pressure; $P_{\text {mus }}$ : Respiratory muscle pressure; $P_{\text {occ: }}$ Occlusion pressure; PS: Pressure support; PTP $_{\text {es }}$ : Pressure time product of esophageal pressure; RR: Respiratory rate; SD: Standard deviation; WOB: Work of breathing.

\section{Acknowledgements}

Not applicable.

\section{Authors' contributions}

Data acquisition: LR; data analysis: LR; data interpretation: all authors; manuscript drafting and revising: all authors. All authors read and approved the final manuscript.

\section{Funding}

There was no financial funding.

\section{Availability of data and materials}

The datasets used and analyzed during the current study are available from the corresponding author on reasonable request.

\section{Ethics approval and consent to participate}

Due to standard patient care and the urgent need to gain knowledge about this new lung disease, informed consent was deemed unnecessary, but also not feasible in most cases. 


\section{Consent for publication}

Not applicable.

\section{Competing interests}

The authors declare that they have no competing interests.

Received: 28 October 2020 Accepted: 29 January 2021

Published online: 08 February 2021

\section{References}

1. Goligher EC, Dres M, Fan E, Rubenfeld GD, Scales DC, Herridge MS, et al. Mechanical ventilation-induced diaphragm atrophy strongly impacts clinical outcomes. Am J Respir Crit Care Med. 2018:197(2):204-13.

2. Goligher EC, Fan E, Herridge MS, Murray A, Vorona S, Brace D, et al. Evolution of diaphragm thickness during mechanical ventilation. Impact of inspiratory effort. Am J Respir Crit Care Med. 2015;192(9):1080-8.

3. Hooijman PE, Beishuizen A, Witt CC, de Waard MC, Girbes AR, Spoelstrade Man AM, et al. Diaphragm muscle fiber weakness and ubiquitinproteasome activation in critically ill patients. Am J Respir Crit Care Med. 2015;191(10):1126-38.

4. Jaber S, Petrof BJ, Jung B, Chanques G, Berthet JP, Rabuel C, et al. Rapidly progressive diaphragmatic weakness and injury during mechanical ventilation in humans. Am J Respir Crit Care Med. 2011;183(3):364-71.

5. Goligher EC, Brochard L, Reid WD, Fan E, Saarela O, Slutsky AS, et al. Diaphragmatic myotrauma: a mediator of prolonged ventilation and poor patient outcomes in acute respiratory failure. Lancet Respir Med. 2019:7(1):90-8.

6. Goligher EC, Dres M, Patel BK, Sahetya SK, Beitler JR, Telias I, et al. Lung and diaphragm-protective ventilation. Am J Respir Crit Care Med. 2020.

7. Vaporidi K, Akoumianaki E, Telias I, Goligher EC, Brochard L, Georgopoulos D. Respiratory drive in critically ill patients. Pathophysiology and clinical implications. Am J Respir Crit Care Med. 2020;201(1):20-32.

8. Goligher EC, Jonkman AH, Dianti J, Vaporidi K, Beitler JR, Patel BK, et al. Clinical strategies for implementing lung and diaphragm-protective ventilation: avoiding insufficient and excessive effort. Intensive Care Med. 2020;46(12):2314-26.

9. Bertoni M, Telias I, Urner M, Long M, Del Sorbo L, Fan E, et al. A novel non-invasive method to detect excessively high respiratory effort and dynamic transpulmonary driving pressure during mechanical ventilation. Crit Care. 2019:23(1):346.

10. Gattinoni L, Chiumello D, Caironi P, Busana M, Romitti F, Brazzi L, et al. COVID-19 pneumonia: different respiratory treatments for different phenotypes? Intensive Care Med. 2020;46(6):1099-102.
11. Guan WJ, Ni ZY, Hu Y, Liang WH, Ou CQ, He JX, et al. Clinical characteristics of coronavirus disease 2019 in China. N Engl J Med. 2020:382(18):1708-20.

12. Pickkers P, van der Hoeven H, Citerio G. COVID-19: 10 things I wished I'd known some months ago. Intensive Care Med. 2020;46(7):1449-52.

13. Baydur A, Behrakis PK, Zin WA, Jaeger M, Milic-Emili J. A simple method for assessing the validity of the esophageal balloon technique. Am Rev Respir Dis. 1982;126(5):788-91.

14. Mauri T, Yoshida T, Bellani G, Goligher EC, Carteaux G, Rittayamai N, et al. Esophageal and transpulmonary pressure in the clinical setting: meaning, usefulness and perspectives. Intensive Care Med. 2016;42(9):1360-73.

15. Akoumianaki E, Maggiore SM, Valenza F, Bellani G, Jubran A, Loring SH, et al. The application of esophageal pressure measurement in patients with respiratory failure. Am J Respir Crit Care Med. 2014;189(5):520-31.

16. Brochard L, Slutsky A, Pesenti A. Mechanical ventilation to minimize progression of lung injury in acute respiratory failure. Am J Respir Crit Care Med. 2017; 195(4):438-42.

17. Doorduin J, Nollet JL, Vugts MP, Roesthuis LH, Akankan F, van der Hoeven $J G$, et al. Assessment of dead-space ventilation in patients with acute respiratory distress syndrome: a prospective observational study. Crit Care. 2016;20(1):121.

18. Telias I, Junhasavasdikul D, Rittayamai N, Piquilloud L, Chen L, Ferguson ND, et al. Airway occlusion pressure as an estimate of respiratory drive and inspiratory effort during assisted ventilation. Am J Respir Crit Care Med. 2020:201(9):1086-98.

19. Roussos CS, Macklem PT. Diaphragmatic fatigue in man. J Appl Physiol Respir Environ Exerc Physiol. 1977;43(2):189-97.

20. Spinelli E, Mauri T, Beitler JR, Pesenti A, Brodie D. Respiratory drive in the acute respiratory distress syndrome: pathophysiology, monitoring, and therapeutic interventions. Intensive Care Med. 2020;46(4):606-18.

21. Bellani G, Grassi A, Sosio S, Foti G. Plateau and driving pressure in the presence of spontaneous breathing. Intensive Care Med. 2019;45(1):97-8.

22. Bellani G, Grassi A, Sosio S, Gatti S, Kavanagh BP, Pesenti A, et al. Driving pressure is associated with outcome during assisted ventilation in acute respiratory distress syndrome. Anesthesiology. 2019;131(3):594-604.

\section{Publisher's Note}

Springer Nature remains neutral with regard to jurisdictional claims in published maps and institutional affiliations.

\section{Submit your manuscript to a SpringerOpen ${ }^{\circ}$ journal and benefit from:}

- Convenient online submission

- Rigorous peer review

- Open access: articles freely available online

- High visibility within the field

Retaining the copyright to your article

Submit your next manuscript at springeropen.com 